\title{
LETTER
}

\section{Renal replacement therapy: is it effective in critically ill patients with acute kidney injury?}

\author{
Helmut Schiff*1 and Susanne M Lang² \\ See related research by Clec'h et al., http://ccforum.com/content/16/6/R236/abstract
}

Clinicians caring for critically ill patients with acute kidney injury (AKI) face two critical questions on reading the article by Clec'h and colleagues [1]: can it be true that renal replacement therapy (RRT) lacks efficacy in these patients; and, if so, should current practice be changed? Regrettably, the authors provided no compelling hypothesis for why RRT did not reduce in-hospital mortality.

The most critical disadvantage of propensity score matching is that this technique can only account for observed covariates, not unobserved covariates, which may cause bias. Furthermore, there are numerous limitations to the analysis: inclusion of patients with chronic kidney disease stages I and II (defined by the estimated glomerular filtration rate), misclassification of AKI (only creatinine criteria), cause of AKI not given, late initiation of RRT, no measurements of the dose, and substantial advances in intensive care during the study period (1997 to 2009).

Critically ill patients with AKI face excessive death rates even in the early stages of AKI that cannot be reversed by RRT. AKI induces and multiplies distant organ dysfunction by induction of inflammatory cascades and oxidative stress. No prospective randomized trial has to date tested the hypothesis of whether earlier initiation of RRT reduces mortality for ICU AKI patients.

During the Korean War, systematic dialysis in AKI reduced mortality from $90 \%$ to approximately $50 \%$.
Although circumstantial, this reduction remains the best available evidence that dialysis improves outcomes for critically ill patients with AKI [2]. There is no doubt that provision of adequately initiated and adequate-dose RRT is life-sustaining in ICU patients [3].

\section{Abbreviations}

AKI, acute kidney injury; RRT, renal replacement therapy.

\section{Competing interests}

The authors declare that they have no competing interests.

\section{Author details}

'Department of Internal Medicine IV, University of Munich, University Hospital Munich, Ziemssenstraße 1, D-80336 Munich, Germany. ${ }^{2}$ Medizinische Klinik 2, SRH Wald-Klinikum, Straße des Friedens 122, D-07548 Gera, Germany.

Published: 31 January 2013

\section{References}

1. Clec'h C, Darmon M, Lautrette A, Chemouni F, Azoulay E, Schwebel C, Dumenil AS, Garrouste-Org, Goldgran-Toledano D, Cohen Y, Timsit J-F: Efficacy of renal replacement therapy in critically ill patients: a propensity analysis. Crit Care 2012, 16:R236.

2. Schrier RW, Wang W, Poole B, Mitra A: Acute renal failure: definitions, diagnosis, pathogenesis, and therapy. J Clin Invest 2004, 114:5-14.

3. Schiff H, Lang SM, Fischer R: Daily hemodialysis and the outcome of acute renal failure. N Engl J Med 2002, 346:305-310.

\section{doi:10.1186/cc11928}

Cite this article as: Schiffl H, Lang SM: Renal replacement therapy: is it

effective in critically ill patients with acute kidney injury? Critical Care 2013, $17: 410$.
*Correspondence: h-schiffl@t-online.de

'Department of Internal Medicine IV, University of Munich, University Hospital

Munich, Ziemssenstraße 1, D-80336 Munich, Germany

Full list of author information is available at the end of the article 